\title{
A Matter of Attitude
}

\section{Reflections on Phenomenology and Media Culture}

\author{
ANDRÉ JANSSON
}

Time has showed that one of the most pertinent concepts emanating from the phenomenological works of Edmund Husserl is the 'natural attitude', theoretically developed in his first magnum opus Ideas (1913/1982). Along with the concept of the 'lifeworld', which became the leading theme of the first part of Husserl's second major work The Crisis of European Sciences and Transcendental Phenomenology (1970), first appearing in 1936 in the journal Philosophia, the natural attitude stands out as a key word to the understanding of his philosophy of everyday life. Additionally, the conceptualizations of Husserl have been central not only in subsequent phenomenological theories of followers such as Schutz, but also within several associated scientific areas, like philosophical anthropology, philosophy of science, psychology and the social sciences (cf. Kockelmans, 1986). As one says, good concepts travel well.

Within media and cultural studies, however, the original phenomenological conceptual framework has rarely been picked up, despite the prevailing focus on practices and perceptions of everyday life. This condition, I believe, is not a result of deliberate neglect or ignorance, but must be traced to the theoretical roots of cultural studies - primarily found in Marxism and semiotics. Hence, taking its point of departure in the classical works of Husserl, this article has the aim of stressing how phenomenological thought can help us better understand and describe the implications of contemporary media culture in everyday life. Above all, the article can be seen as an attempt to outline a framework for the application of phenomenology in the study of cultural consumption. Using two ethnographic interviews about media habits as empirical illustrations, the possibilities of linking phenomenological concepts to prevailing sociological notions of lifestyle and identity will be explored. Such linkages may help us overcome the gap between micro and macro perspectives in audience studies, as well as the more general gap between theoretical philosophy and the cultural sciences.

\section{The Natural Attitude and It's Dynamics}

The natural attitude can be defined as a particular mode of consciousness, in which the individual approaches his or her surrounding world as a world of taken for granted phenomena - phenomena whose existence is not put into question, because they are always there (as they always are), in the particular order that the individual has got used to through lived experience. To be in the natural attitude, hence, is to be in a state of nonreflexivity, co-ordinating one's actions on the basis of routines which in their turn are the outcomes of initial reflexive adjustments to the circumstances of the surrounding world. 
The qualities and the very existence of new, unfamiliar objects must be evaluated and incorporated as aspects of the individual's routinized schemes of interpretation before they can be approached in the natural attitude, that is, before they can become part of the taken for granted reality, the lifeworld. The way these objects appear to the individual in the natural attitude, due to their specific qualities and position among other objects, is the way they are actually considered to be. They are there, taken for granted, in their pure essence as phenomena.

However, the lifeworld cannot be restricted to the immediate, surrounding world of touchable physical things, what Husserl in Ideas refers to as the 'natural world'; this domain had not been taken for granted if it had unveiled itself in isolation, disconnected from the individual's previous experiences. Accompanying all social and physical activities are actualities not directly in the field of perception, but existing merely as phenomena inside people's heads. These phenomena constitute what Husserl (ibid.: 52) describes as an 'infinite, misty and never fully determinable horizon' - an accumulated stock of knowledge, in itself taken for granted, composed according to individually appropriated views of the world. Without this experientially derived horizon of interpretation it should not be possible to make sense of the world 'on hand', nor face it as something pregiven.

Nor is the lifeworld a stable entity. As new phenomena are encountered and eventually taken up as parts of the taken for granted stock of knowledge its composition is gradually altered, although it still remains one and the same. This transitory process goes on constantly as people proceed their lives; sometimes without their notice, sometimes involving great psychosocial turbulence, as in occasions of major shifts or ruptures in life. New components are brought in all the time, while others are eroding or put into question, forming a double movement of inclusion and exclusion, through which the scope of the interpretative horizon is reworked. Discussing the first matter - what may be called the problem of inclusion - Husserl (ibid.: 54-5) stresses that even entire new worlds, fields totally separated from the world of 'real actuality', can be appropriated. Taking the knowledge of arithmetic as an illuminating example, he points out that if the skills necessary to master the rules of this world are obtained, it can be approached in a mode of consciousness congruent to the natural attitude. The individual can then fully engage his or her thoughts in the 'arithmetical world', surrounded by a 'partly indeterminate arithmetical horizon', being in the 'arithmetical attitude'. In this way it is possible to shift focus of attention, altering between different attitudes - always returning to the natural attitude:

If my cogito is moving only in the worlds pertaining to these new attitudes, the natural world remains outside consideration; it is a background for my act-consciousness, but it is not a horizon within which an arithmetical world finds a place.

Thus, in this example - chosen for the sake of its clarity - there is no connection between the natural world and the new, appropriated world; their horizons have nothing in common. Or, to put it in yet one equivalent way; the stock of knowledge required to interact with the natural world is of no use in the arithmetical world, and vice versa. Nonetheless, as I will shortly return to, there are several domains of life where such an interpretative independence is not present.

The question of exclusion involves a rather precarious philosophical consideration, based on the fact that the individual cannot eliminate, or erase, a phenomenon that is at the same time taken for granted. Of course, as pointed out above, certain phenomena, which in a particular life stage are taken for granted, may naturally be brought to the 
more misty regions of the interpretative horizon; they actually cease to exist, or are lost out of sight and simply forgotten. For example, the individual cannot fully take the position of the child he or she once was, although still being in the same world. But a deliberate phenomenological elimination can never take place, even if there may be instances in life when certain facts are repressed. The nearest one can get a conscious erasure of something that is already taken for granted, according to Husserl (ibid.: 59-60), is to doubt it, or, rather, 'attempt to doubt' it (since its existence one can not deny in the first place). What one actually does, is doubting its qualities as a phenomenon, or modifying its position among other phenomena; excluding, or parenthesizing, it. The phenomenon is still there, existing, but appears 'like the parenthesized in the parentheses, like the excluded outside the context of inclusion'. As will be demonstrated below, a central feature of media culture is people's desire to limit the amount of taken for granted media phenomena.

\section{The Perception of Media Products as Phenomena}

In the beginning of the century, when Husserl first advanced his ideas of the natural attitude, it did hardly exist any media to take for granted; even the magnitude of print media was limited, primarily consumed among the educated strata of society. The natural surrounding of people's everyday lives did not include TV sets, VCRs, radio clocks, stereo systems, walk-mans, computers and so on - things that most people in the contemporary modern world consider as customary. Hence, the media development is a significant example of how the lifeworld is constantly reworked. In this case the transitory force is primarily structural, linked to technological progress, changing the life circumstances for millions of people.

Although the appearance of new communication technology is not the only way in which the lifeworld has got transformed during the last century, it might be the most interesting one. People have not only refurbished the physical domains of everyday life, acquired new objects to the domestic sphere, but have also got access to new cultural worlds and thereby changed their perception of time and space (cf. Harvey, 1989; Meyrowitz, 1985; Thompson, 1995). The vast range of different media content have made visible unfamiliar places and events, spatially and/or temporally distant, as well as entirely imaginary, fictive realities. What is more, following the phenomenology of Husserl, since the interpretation of, or the mere being in these new worlds, requires particular patterns of knowledge, their appropriation must also involve the appropriation of a whole set of new media related attitudes - modes of consciousness similar to the natural attitude, but to a certain extent following their own rules. This, in turn, implies that the concept of media phenomenon, as a type, must be designated to two different levels of perception; that of the natural attitude and that of the more confined and focused media attitude. How a particular medium and its content are experienced in a particular moment is not determined by the media characteristics alone, but follows also from the attitude in which the reader, listener or viewer approach it.

When perceived in the natural attitude, the essence of the media phenomenon comes forth merely as one component among others in the natural world 'on hand'. People take for granted that media products, both in shape of physical objects, or technologies, and as texts (using the term in its broadest sense), surround them almost wherever they are. In the domestic sphere media products are included in the furniture, occupying spaces corresponding to the functions assigned to them. The colour TV in the corner of the living room, the transistor radio in the kitchen, the computer on the desk; they are all natu- 
ralized objects of the lifeworld, though their typical locations may vary according to the spatial conditions of the home, and between different groups (cf. Moores, 1988; Silverstone et al., 1992). Additionally, since the practical use of mass media often has the character of a secondary activity, being part of people's non-reflexive everyday rituals, or functioning as environmental resources (cf. Lull, 1990), the very content of mass media can also be perceived in the natural attitude. This especially holds true for radio, which is often heard, rather than listened to (Larsen, 1997). In these instances the media text becomes a part of the natural world.

In a similar manner, in many domains of the public sphere people expect themselves to be surrounded by various media products. The music they hear (but hardly notice) in the department store, the free newspapers they get when boarding the airplane, and the advertising signs they pass by in the city on their way home from work are just a few examples. The existence of these media phenomena is not made the object of hermeneutic reflection (unless it is someone's first encounter with a department store, an airplane or a modern city landscape). But if they were taken away - something should be missing.

The distinction between the natural attitude and the particular media attitude corresponds to the distinction between 'hearing' an 'listening to' the radio. When someone shifts his or her mode of consciousness from the first to the latter, it signifies a shift from a mode in which the media product is just one phenomenon among others in the direct physical surrounding, to a mode in which the individual becomes a reader (in semiotic terms). This happens when someone starts paying attention to what is actually presented on TV, or what they are actually saying on the radio - when the product becomes meaningful not only as an environmental background to other practices, but also as a text in its own right. The media consumer enters into the discursive world of the particular media text. However, this does not mean that he or she has to give up all other activities that may be conducted at the same time. It is perfectly possible to wash the dishes while also listening to a discussion on the radio. Analytically speaking, in such a case radio listening (as opposed to hearing) ought to be called a 'primary activity' rather than a 'secondary activity'. The latter concept has often been bluntly used to simply denote a situation in which a person is 'doing two things at the same time' - whatever that may be.

Moreover, being in the media attitude is not the same thing as simply being attentive to a particular text; it connotes that the audience member enters a symbolic world with a particular structure, whose characteristics are taken for granted. Just as the pregiven stock of knowledge about the natural world enables people to act in that world, being focused on the particular action that may be performed, the interaction with the world of media texts cannot be meaningful without a certain cultural, or, rather, media particular competence. The reader can focus on the evolution of the text (e. g. the narrative of a film) while being non-reflexive regarding the discursive conventions through which the text speaks itself. This is a central point, making the media attitude an analytical correlate of the natural attitude.

But what exactly is it that a media consumer take for granted when being in the media attitude? Clearly, there are a multitude of different conventions that do not need to be reinterpreted every time someone encounters a particular media product. And precisely because such conventions are not often reflected upon, they may be tricky to crystallize. Roughly, however, they can be traced to three main levels: First, there are conventions linked to the medium as cultural form. Watching television is not the same thing as reading a newspaper. The audience does not expect to see moving images or hear sounds from the newspaper, to make a trivial statement. Each medium has its own particular 
characteristics, which are fundamentally based in, or limited by, its physical properties - and all these standards are well known to the accustomed audience. This is not to say that they are stable or entirely independent from one another; although the technical features of a medium remain basically the same, the limits of the means of using them are continually contested by the producers. As for example Williams (1974) pointed out in his essay on television, the characteristic segmentation of early broadcasting, which separated programmes by distinctive breaks, was eventually reworked. In order to keep the viewers stuck by their TV sets, essentially for commercial reasons, the programming was successively arranged more like a flow, eliminating the 'dead' time between the programme spots by smooth audio-visual bridges, like announcements, trailers and commercials.

Second, the media attitude involves a knowledge about generic conventions. When encountering a particular text, for example an episode of a soap opera, the audience has certain expectations as to what that text will contain (the narrative) and how it will be structured (the discourse). In the case of the soap opera the viewer expect there to be (however he or she is not fully aware of it) a certain melodramatic atmosphere, a certain rhythm of sequences, a certain use of camera close-ups, a certain use of background music, etc. (cf. Ang, 1985; Geraghty, 1991) - generic conventions that he or she does not reflect upon, but which all the same govern the sense making of the text. In the same manner people employ particular horizons of expectation when reading the business pages, listening to a radio newscast, or entering a fanzine site on the Internet. All these generic competences are created from previous experiences of media use, and can thus be reworked as the genres themselves are reworked. As stated in literary and film theory, the genre is not a stable category, but relies fundamentally on intersubjective agreements between the author and the reader of the text (cf. Todorov, 1978/1990; Neale, 1990).

Third, being in the media attitude implies a taken for grantedness of different text specific characteristics. When watching a news spot on CNN, or the latest episode of Seinfeld, the sense making is not only dependent upon the viewer's knowledge about TV news or sitcoms in general, as genres, but also upon his or her experiences of CNN news and the Seinfeld sitcom in particular. For example, it is taken for granted what the news room looks like and who the news presenters are, and, likewise, there is a familiarity with the settings and the particular funny characters of Seinfeld. Serialized media products like these (the same thing can be argued for newspapers, magazines, etc.) build a great deal of their popularity upon the audience's recognition of familiar symbolic patterns - patterns that are unique for the particular text, distinguishing it from other texts within the same genre, while still remaining in that very genre.

The demarcation lines between these three levels are not easy to figure out, not even on a strictly theoretical level. And when reading a media text, being in the media attitude, knowledge about the conventions of all three levels are applied at the same time. The TV viewer cannot 'turn off' his or her knowledge about television as cultural form when watching a TV programme, as little as it is possible to turn off the knowledge about grocery stores in general ('the grocery store as genre') when visiting the particular Konsum grocery store across the street. To use Husserl's vocabulary, the individual's accumulated media competences surround him or her as an infinite, misty and never fully determinable horizon of interpretation, and normally one does not bother about how this horizon is actually composed. Just as Goffman and the ethnomethodologists have showed regarding the norms of different social arenas (cf. Garfinkel, 1967/1984; Goffman, 1974), people do not recognize media conventions until someone is breaking 
the rules. The day when the weather girl on TV starts picking her nose people will be as surprised as the day when Konsum starts giving away vegetables.

\section{Cultural Leakage}

Although the world of media texts is a world separated from the natural world, it would be wrong to consider it as entirely autonomous (like the arithmetic world discussed by Husserl). As has already been pointed out, although there are significant rules and conventions, these are not absolute or stable, but flexible and negotiable, founded upon the intersubjectivity between producer and audience. Additionally, and more important, there is a certain mutual influence, or a 'cultural leakage', between the stock of knowledge framing the natural attitude and the corresponding stock of knowledge framing the media attitude. On the one hand, people do always bring some of their common sense knowledge about the natural world with them into the world of media texts, which implies that the text does not unfold itself in an isolated symbolic sphere, referring to nothing but itself and the generic structurgs in which it is positioned. Indeed, even in science fiction movies there are cultural categories - such as gender patterns, themes of love and hate, good and evil, and so forth - that most people can associate to the world as they know it from their lived experience. And since people may have different experiences of such categories, this also indicates that the meanings they create from media texts rely on interpretations that are culturally conditioned, that is, relative to the unique composition of cultural experiences that individuals have from an array of different arenas. As has been thoroughly investigated within the field of media reception analysis, different cultural groups, and, ultimately, different individuals, interpret one and the same text in culturally specific ways (cf. Morley, 1980; Hobson, 1982; Liebes and Katz, 1990).

On the other hand, there is also a range of symbolic elements emanating from the world of media texts, leaking into the cultural horizon of the natural world - an emanation that must be advanced as one of the most significant features of modern media culture. Living in a media saturated world, in which the consumption of media texts takes place within the physical settings of everyday life, media phenomena tend to be appropriated not only within the framework of the media attitude, but also as parts of the cultural knowledge governing people's day-to-day activities, their lifestyles. For example, in social life people continuously, and to an increasing extent, encounter phenomena that can be associated to the world of media texts; they are discussing TV programmes at work, they start incorporating catch phrases from TV ads in their manner of speech, and so forth. In this way people are constantly, indirectly perceiving elements of media products when being in the natural attitude - in addition to the direct experiences described above. Accordingly, the cultural categories that can be learned from mass media shape a good deal of people's understanding of the natural world, and contribute to the creation of cultural identity. The symbolic goods distributed by mass media may even function as the common denominators holding together cultural communities that are uncoupled from the spatial-physical restrictions of direct social interaction - a particular form of 'imagined communities' (cf. Anderson, 1983). This is exactly what media culture is about; it is a culture in which a significant share of the people's perception of themselves and their lifeworld, as well as the relationship between themselves and their lifeworld the relationship through which an individual identity is defined - is influenced by the symbolic world of mass media (cf. Kellner, 1995: 1). 
How, then, does this discussion relate to Husserl's original conceptualization of the lifeworld? To what extent is the world of media texts to be considered as a part of the lifeworld? Answering this question, one must bear in mind that Husserl did not fully develop the concept of the lifeworld until The Crisis (1936/1970), and that the concept, even as it is presented in that major work, contains certain contradictions. For example, Carr (1977) argues that Husserl never really succeeded in relating the world of culture, the world of our immediate experiences, and the world of science - precisely the kind of association apprehended in the above question. Yet, as Bidney (1973) points out, the lifeworld concept is precisely the concept that carries the potential of reconciling phenomenology and the cultural sciences. As the lifeworld is described in The Crisis, and later on by Schutz (1962; see also Schutz and Luckman, 1973), it does not only comprise the naturally selected environment, the 'natural world', but also the social and cultural world of human society - what may be referred to as the cultural lifeworld, that is, 'an intersubjective system of meaningful experiences, institutions, activities, symbolic expressions of ritual and art, together with their products' (Bidney, 1973: 133-4). The cultural lifeworld can be defined as the composite of an individual's hermeneutic skills, derived both from actions and interactions in the natural world, and from engagement in the world of media texts (or other texts). It includes the meaningful experiences from everyday life employed when reading a particular text, as well as the mediated experiences employed when interpreting the natural world. Thus, the interdependence I have outlined between the natural attitude and the media attitude involves some of the processes through which the cultural lifeworld evolves - spanning, or blurring, the boundaries between the natural world and the world of media texts. One may even consider the extent to which the interpretative horizon framing the media attitude fuses with the interpretative horizon framing the natural attitude as a hypothetical measure of the mediatization of everyday life.

However, the fact that elements from the world of media texts continually leak into people's everyday lifeworld can sometimes be considered as problematic. In a study of young adults' experiences of advertising in everyday life, O'Donohoe (1997) found that many of the respondents thought it was difficult, not to say impossible, to escape the non-desirable presence of commercial messages. Advertising was experienced as 'omnipresent, seeping into the fabric of their everyday lives' (ibid.: 272) - a fact that to a certain extent could be traced to advertising's intertextual relationship to other media texts, that is, its indirect presence in for example TV programmes and newspaper articles; being a common sphere of reference. O'Donohoe's results provide a good illustration of a problem that can not be restricted to the domain of advertising, but is representative for contemporary media culture as such. It illustrates the condition that people often would prefer not to take for granted the things they actually do take for granted - their desire to reject certain phenomena from being incorporated within the horizons of the lifeworld, or exclude phenomena that are already there.

\section{Coping with Media Culture: The Lifestyle-Lifeworld Relationship}

Today it is possible for anyone to take part of the media flow 24 hours a day - destining himself or herself to become a non-stop media consumer, absorbed into the world of media texts. But still, although a 'media addict' eliminating his or her social life, that person would just consume a microscopic share of the total available output of media products. Hence, in order to cope with the gigantic overproduction of symbolic goods, people need to design their lives in a manner through which they habitually can keep 
non-wanted objects out of their lifeworld. Every person must reject the media flow through the establishment of a routinized lifestyle. Applying the social psychological perspective of Giddens (1991), the lifestyle can be considered as a coping mechanism, through which the individual manages to keep up a sense of personal autonomy and continuity, a sense of ontological security, in a dynamic and pluralized world. It is through the maintenance of a coherent lifestyle, a certain formula for the composition of everyday practices, that people incorporate and establish new meaningful elements in their lifeworlds, adjusting their cultural horizons. Thus, Giddens' notion of ontological security is congruent to the idea of the lifeworld: both concepts point at the individual need for a controllable life environment. However, as showed in O'Donohoe's study, in relation to the contemporary bombardment of media products routines are not always enough; fragments of non-wanted media products often leak into everyday life somehow indirectly. One may then experience a sense of frustration as to one's own incapability of fully governing the processes through which the lifeworld is composed.

This section presents an empirically grounded account of how people in different social contexts through their lifestyles cope with media culture in everyday life, and how they do not cope with it. My aim is not to give a generalized picture of the broad sociocultural patterns of contemporary society, but to demonstrate how the phenomenological conceptualizations presented above can provide the framework for a concrete empirical investigation of the processes of everyday culture. Accordingly, to make my point clear, I will use only two qualitative interviews as distinct examples. These are chosen among a total of 42 qualitative interviews that are part of the research project Cultural Identities in Transition (CIT), conducted at the Department of Journalism and Mass Communication, University of Gothenburg. The interviews, about one hour each, were carried out in 1997 and 1998, addressing a broad range of questions focusing on lifestyle and media use.

The two respondents I have chosen as examples, Petra and Felicia, do not have very much in common: Petra is 24 years old and has lived most of her life in the working class suburbs of Gothenburg. She has had various occupations during the last five years, mainly working as a nurse and as a shop assistant in a grocery store. One year ago she lost her job, so now she is back in school to improve her education. She has also been engaged, but is currently single, living in a typical suburban apartment about 30 minutes from the city of Gothenburg. Felicia, on the other hand, is a university lecturer in her 50 s, living in an old apartment in one of the culturally prestigious areas of the inner city. Previously she lived in a house by the sea with her husband and their four children, but now she is divorced, living together with her youngest daughter. In other words, the comparison introduces two women in different stages of life, occupying very different positions in social space.

\section{Routinized Modes of Perception}

One central aspect of how people compose their cultural lifeworld is the mode of consciousness in which they prefer to approach mass media products; whether they want to be in the natural attitude or in the media attitude when perceiving them. In general terms, the ways in which people use mass media change successively as new media technologies are introduced. For example, when television was naturalized in the domestic sphere, people started using the radio in new ways, notably as a background medium. But there are also considerable variations between individuals according to age/genera- 
tion, life situation, social position and living conditions - factors that determine the overall lifestyle (cf. Andersson and Jansson, 1998).

Felicia represents both a generation and a social group for whom mass media are rarely conceived of as an environmental resource. She says that she prefers to be concentrated on what she is doing, and assigns the habits of zapping between TV channels and using TV as an audio-visual wallpaper to the younger generation. In other words, she feels distracted when encountering media products (apart from the physical objects) in the natural attitude; media sounds are considered as disturbances, because they actually bring her out of the natural attitude. So far, she has not even used the radio as a background medium, although she is willing to modify her lifestyle in that respect planning to buy a radio, so she can listen to the cultural programmes of P1 (one of the four national public broadcasting channels). However, this is something very different from just hearing the radio:

F: I think I will buy a transistor radio quite soon, so I can listen more to the radio. I don't do that very often, I haven't got used to it. But now when I'm getting closer to retirement, I think I will get more free time, and then I will listen more to the radio. There are lots of programmes that attract me [mentioning a couple of philosophical and cultural programmes on P1].

I: [...] How come you haven't had a radio before? Because you could actually have one now...

F: Yes, I could. But I'm not used to that. Some people have the radio turned on all the time. But I haven't got used to that. When I have listened, then I have listened, you know. I have been concentrated on what I've been doing... I've never taken up those other habits. And it's nothing I strive for either, having some constant buzz turned on... But perhaps when I do certain things, like the dishes or so, then I could have the radio turned on in the background.

The concern to keep the natural world free from disturbances, like the buzz of the radio and the TV, is underlined by her media preferences. She reads the local newspaper very carefully in the morning, and sometimes several more papers at the university. Her TV preferences attain a focus on cultural programmes, films and news - categories that demand a certain degree of concentration from their viewers. Since Felicia is also a regular visitor of art galleries, theatres and the cinemas offering 'quality films', her lifestyle represents the classical embodiment of cultural capital (cf. Bourdieu, 1979/1984).

For Petra the world of media texts is appropriated in a more dualistic way. On the one hand, it is a world to which she can escape through TV series and films, 'dreaming away', leaving the troubles of everyday life behind. The drama of television make the natural world temporarily vanish from her field of perception; she is completely in the media attitude. She watches at least one soap opera a day (several more on Saturdays and Sundays) - almost exclusively American productions. On the other hand, when she is not absorbed by TV dramas, she allows the world of media texts, that is, in her case, only television, to embrace her everyday life, blending together with the natural world:

P: Since I'm alone here I want to have something turned on all the time, you know. So I have sound in the background. [...] I wouldn't stand it alone if I hadn't had TV. I mean, if you walk around in the flat, especially... this big flat I think... I should 
walk around here like a ghost if hadn't had something turned on... something talking, kind of. I would have gone mad. I'm glad I wasn't born 200 years ago!

In Petra's lifeworld television has completely superseded the social function of radio. Petra never listens to the radio at home, except for a short while in the morning when the radio clock wakes her up. As she explains it, 'I must have colours, you know [...] I have always liked colours, shapes pictures'. Thus, television does not simply occupy the same function as radio, but something more. Its visual properties are essential, since they actively contribute to the aesthetic shape of her home environment, and at the same time provide a kind of company. Most of the time when the TV is on she does not engage in the text itself; the important thing is that it is there. The familiar sounds and pictures together create a taken for granted framework that makes her feel ontologically secure - a kind of confirmation of her own existence. As she says, 'the home is my castle'.

\section{The Cultural Horizon of the Lifeworld}

Following the pattern of her preferences, Felicia's cultural competences are mainly restricted to the world of newspapers and 'high culture'. She also finds it of central concern to maintain and develop these competences, while having no interest in broadening her scope to the popular cultural field. The way she discusses for example movies indicates that she holds a great capacity of interpreting abstract symbolic themes and intertextual relationships within the field of art, and that such patterns of association are fundamental to the joy of cultural consumption. Thus, her frames of reference have much in common with the regular visitors of art museums, studied by Bourdieu and Darbel (1969/1991). When having the appropriate cultural skills, being able to position the particular object in relation to other objects within the same field or genre, the consumption of fine arts becomes a matter of natural pleasure, rather than a puzzling experience. However, it is only a minor group in society, people with large amounts of cultural capital (that is, socially legitimized cultural competences), who retain this ability to take artistic conventions for granted. Felicia can be counted as one of these 'happy few'. Symptomatically, she takes the advice of the film critics of the newspapers - people who maintain a similar taste, and a similar cultural horizon as herself.

Comparing Felicia's and Petra's perception of Göteborgs-Posten (Gothenburg's major daily newspaper) provides a good illustration of how the cultural horizons of their media attitudes are composed. While Felicia keeps herself constantly updated regarding the textual conventions of this newspaper (as well as other ones), Petra's view is founded on experiences that she made several years ago, when reading the paper at work. And while Felicia previously has considered Göteborgs-Posten as a 'rather silly newspaper', Petra finds it 'complicated' and 'boring':

F: Previously I thought Göteborgs-Posten was a rather silly newspaper. And the interests I had in culture and so forth were not covered very much if you go back ten years. They were really bad at these parts, while Dagens Nyheter was following up the cultural situation very well, had good cultural articles. That's why we had it. Now I have changed to GP mostly to get the local information. But I can notice that it has become much better, and the cultural coverage in GP... yes, it is as good as in Dagens Nyheter and Svenska Dagbladet, I would say. And it's also pleasant to read... 
substantial, lots of material. That's how I am. I read the newspaper for one hour almost every morning before I go to work.

P: I read GP when I happen to have one... like when I was working at the hospital, you know, like on a Saturday morning break or something. Then I could have a look. But GP is so complicated...

I: $\mathrm{Mmm} \ldots$

P: It's so big, and there's so much advertising, and furthermore it's black and white. And it's so damn boring... Perhaps it has got some colour now, I think...

Notably, at the time when the interviews were conducted there had been colour pictures and illustrations in Göteborgs-Posten for several years already, indicating that Petra's perception of Göteborgs-Posten as a media phenomenon has been largely unchanged for a long time - perhaps even since childhood. In other words, the picture she recalls of Göteborgs-Posten when being in the natural attitude is related to her inability of approaching the same product in the media attitude. She is not currently familiar with the generic structure. An interesting parallel can be found in a theoretical example of Schutz and Luckman (1973: 70), discussing the character of social memories. Their point is that people while being in the natural attitude do not update their view of a phenomena that has disappeared from their immediate surrounding world, in this example a friend:

I also know that he must have become older, and, when I reflect on it, I also know that strictly speaking he must have changed with every new experience. But in the everyday natural attitude, without reflection I leave all this out of consideration and hold fast to the familiar representation of my fellow-man.

Accordingly, one can consider Petra's last sentence as an act of reflection, in which she modifies the taken for granted view she first expressed. Nonetheless, the first spontaneous account she gives of Göteborgs-Posten clearly represents the dominant picture inside her head, and is therefore the most interesting statement from a phenomenological point of view. Such a typified view reveals a great deal about how she positions various media phenomena in relation to one another - what they actually mean to her.

In a similar manner, Felicia has not updated her knowledge regarding television, which in Sweden has been the subject of considerable change during the 1980's and 1990's. A number of commercial TV channels (one terrestrial and several cable channels) have been added to the two national public service channels SVT1 and SVT2. However, Felicia has not put any effort into exploring these:

I: What's the reason for not watching the news at TV4?

F: Well, I think it's a matter of habit. I've got used to one and two [SVT1 and SVT2]. It's enough. [...] It's mostly a matter of habit. But then, also, I think I have seen it sometime [TV4 news]... and I think the style of one and two suits me better. I don't know... I don't really know what it's like there on TV4.

I: About the other channels outside the public service system... [...] Does it ever happen that you're watching the cable channels?

F: Which ones is it you call the cable channels? 
Once more the interdependency between the media attitude and the natural attitude is illustrated, as well as the coping function of lifestyle habits. Felicia cannot approach the more recently launched TV channels in a non-reflexive mode of perception, since she does not 'really know what it's like there'. Entering the world of commercial television is almost like entering a city in a foreign culture. Consequently, the essence of these channels as taken for granted phenomena, when conceived of in the natural attitude, is defined as an unspecified number of new channels that she is not interested in anyway. She knows that they are there, but her lifestyle does not enable her to differentiate between them.

\section{Conflicts and Frustrations}

Sometimes Felicia watches a film on any of the commercial TV channels - 'if there should be a very special film'. However, at these occasions she finds it very disturbing with the commercials that repeatedly interrupt the film. These are experienced as intruders in her cultural lifeworld, and she tries to avoid, or, rather, exclude them as much as she can:

F: I get very irritated when they interrupt a film, for example. You're watching a film and it gets interrupted three times of commercials. Then I get irritated.

I: Does it happen that you turn off the TV?

F: Yes, I leave... I go out to do something else. Leaving the sofa...

I: To get away...

F: And also, since I often go to the movies I see a lot of advertising there. And... I don't know what to say, but it's so loud and the tempo is so high... It doesn't suit me, it's not my stile. If there should be a commercial that is quiet and peaceful, I think I would take more notice of that.

Since the world of advertising to a great extent is an integral part of the he world of media texts, embedded in TV programmes, radio programmes, movies, newspapers and magazines, it is, just as O'Donohoe (1997) points out, omnipresent - as long as the individual does not choose to stand outside contemporary society completely. As described above, Felicia does not incorporate many cultural elements from the commercial sector of the television system, but in order to take part of the particular cultural events she is attracted by, she sometimes has to encounter the commercial messages. What must be noticed, though, is that she does not consider the ads of newspapers as disturbing elements. This fact can primarily be connected to the cultural form of print media, making it possible for the reader to simply skip the ads. The commercial break on TV, on the other hand, is precisely a break - a sudden interruption in the reading process, demanding a new set of generic competences to be put into work. Furthermore, Felicia has not yet naturalized the existence of televised advertising. While advertisements have always been a constituent part of newspapers and magazines, and are hence already taken for granted, TV commercials are a relatively new phenomenon. The new shape of television requires a reworking of the particular skills governing the viewer's media attitude on the generic level.

Petra does not mention TV commercials as an instance of cultural intrusion. She almost exclusively watches the commercial TV channels, since these are the channels 
where the series she likes are aired. Public service television, on the contrary, is considered as 'disgustingly boring'; watching these channels is as boring as 'trying to find out the meaning of stones'. And since she is living alone, she is able to avoid these channels as much as she wants. Previously, however, when living together with her ex-boyfriend, who was a 'dominant bastard', she often experienced frustration, because she could not see the programmes she wanted to see. Not that her boyfriend was interested in the programmes of SVT - but he was interested in sports:

P: Well I don't watch the same programmes anymore. Because what I wanted to see, he didn't want to see. He... it was a lot of sports, and I hate sports, you know. [...] But he loved Beverly Hills for some strange reason. So I watched it too... [...] He was a rather dominant person, if we say... so he got things the way he wanted.

Petra also says that her ex-boyfriend had more than 300 video films, and was in constant command of the remote control: 'The remote control was his life.' During this period, in order to avoid serious conflicts, she had to watch several programmes that she was not actually interested in. Thus, the composition of her lifestyle was compromised, which in turn led to a modification of her cultural horizon that was not sought after. In the long run, this sense of not being in control of the processes of inclusion and exclusion became a source of social frustration. As has also been reported from several previous ethnographic studies (cf. Morley, 1986; Lull, 1990), the domestic sphere is a field of continuous negotiations between family members, while also very often a site of male dominance. In other words, conflicts and frustrations may appear as to whose ideal lifeworld shall become the dominating one. When living under the same roof, individuals have to accept the influence of other people's cultural preferences, taking for granted much of the same things that they do. The sphere of domestic family life must therefore be regarded as one of the most complex sites of contemporary media culture - a site in which the coping function of the lifestyle is challenged.

\section{Concluding Remarks}

I have in this article tried to advance the benefits of integrating phenomenological conceptualizations within the field of cultural studies in general, and audience studies in particular. Through the empirical application presented above, though being a very brief example, I have also demonstrated the possibility of such an integration. While the strength of phenomenological theory is its ability of structuring the cognitive complexity of individual knowledge, experience and action, putting the living subject in the centre of analysis, it is also compatible with the predominant ethnographic and cultural sociological research traditions. Especially the concepts of the lifeworld and the natural attitude enable cultural inquiry to approach processes of everyday life from new, subjectivistic angles, without turning its back on more contextual, or structural, questions.

To further integrate phenomenology into cultural research, there are a number of different ways to go. I have already showed how the sociology of for example Giddens and Bourdieu are worth considering as complementary frameworks. Other theorists, like for example Habermas (1987) and Berger et al. (1974), have already provided broad accounts of how phenomenological concepts, in particular the lifeworld concept, can be appropriated as analytical tools in a wider sociological context. Following the intellectual path of Habermas, it would be interesting to develop a more culturalistic notion of his thesis of the systems' colonization of the lifeworld, and the exhaustion of communi- 
cative rationality. Especially against the backdrop of people's scepticism towards advertising, demonstrated above, this theme ought to be more thoroughly investigated from within the lifeworld itself - focusing directly on people's experiences and potential strategies of cultural resistance.

In a similar manner, Berger's theory of the pluralization of lifeworlds could be developed in a culturalistic direction, focusing explicitly on the processes of cultural, rather than social, pluralization. As pointed out previously, the development of new communication technologies and the parallel expansion of popular culture have opened up new discursive worlds, which people may alternate between just like they alternate between different social arenas. The Internet, or cyber-space, is the latest, and also the most striking, example of this cultural pluralization process - a space in which the user can stroll around like the flâneur of modern city landscapes. Thus, phenomenology is a remarkably timeless business. Since the nature of human consciousness basically remains the same, phenomenology can, and ought to, be adopted in a wide range of research disciplines. And that must not be a matter of attitude.

\section{References}

Anderson, Benedict (1983) Imagined Communities. Reflections on the Origins and Spread of Nationalism. London: Verso.

Andersson, Magnus \& André Jansson (1998) 'The Blurring of Distinctions: Media Use and the Progressive Cultural Lifestyle', Nordicom Review, Winter 1998.

Ang, Ien (1985) Watching Dallas: Soap Opera and the Melodramatic Imagination. London: Methuen.

Berger, Peter; Brigitte Berger \& Hansfried Kellner (1974) The Homeless Mind: Modernism and Consciousness. Harmondsworth: Penguin.

Bidney, David (1973) 'Phenomenological Method and the Anthropological Science of the Cultural LifeWorld', in Natanson, Maurice (ed.) Phenomenology and the Social Sciences, Volume 1. Evanston: Northwestern University Press.

Bourdieu, Pierre (1979/1984) Distinction: A Social Critique of the Judgement of Taste. London: Routledge.

Bourdieu, Pierre \& Alain Darbel (1969/1991) The Love of Art. European Art Museums and their Public. Cambridge: Polity Press.

Carr, David (1977) 'Husserl's Problematic Concept of the Life-World', in Elliston, Frederick \& Peter McCormick (eds.) Husserl: Expositions and Appraisals. Notre Dame: University of Notre Dame Press.

Garfinkel, Harold (1967/1984) Studies in Ethnomethodology. Cambridge: Polity Press.

Geraghty, Christine (1991) Women and Soap Opera: A Study of Prime Time Soaps. Cambridge: Polity Press.

Giddens, Anthony (1991) Modernity and Self-Identity: Self and Society in the Late Modern Age. Cambridge: Polity Press.

Goffman, Erving (1974) Frame Analysis: An Essay on the Organization of Experience. New York: Harper Colophon Books.

Habermas, Jürgen (1987) The Theory of Communicative Action, Volume 2: Lifeworld and System: A Critique of Functionalist Reason. Cambridge: Polity Press.

Harvey, David (1989) The Condition of Postmodernity. An Enquiry into the Origins of Cultural Change. Oxford: Blackwell.

Hobson, Dorothy (1982) Crossroads: The Drama of a Soap Opera. London: Methuen.

Husserl, Edmund (1913/1982) Ideas Pertaining to a Pure Phenomenology and to a Phenomenological Philosophy: First Book: General Introduction to a Pure Phenomenology. The Hague: Martinus Nijhoff Publishers.

Husserl, Edmund (1936/1970) The Crisis of European Sciences and Transcendental Phenomenology. Evanston, Ill.: Northwestern University Press.

Kellner, Douglas (1995) Media Culture: Cultural Studies, Identity and Politics Between the Modern and the Postmodern. London: Routledge.

Kockelmans, Joseph J. (1986) 'Phenomenological Conceptions of the Life-World', in Tymeniecka, Anna-Teresa (ed.) Analecta Husserliana - The yearbook of Phenomenological Research, Vol. XX: The Moral Sense in the Communal Significance of Life. Dordrecht: D. Riedel Publishing Company. 
Larsen, Bent Steeg (1997) Hearing and Listening to the Radio in Everyday Life. Paper presented at 'The $13^{\text {th }}$ Nordic Conference in Mass Communication Research', Jyväskylä August 9-12, 1997.

Liebes, Tamar \& Elihu Katz (1990) The Export of Meaning. Cross-Cultural Reading of Dallas. New York: Oxford University Press.

Lull, James (1990) Inside Family Viewing. Ethnographic Research on Television's Audiences. London: Routledge

Meyrowitz, Joshua (1995) No Sense of Place. The Impact of Electronic Media on Social Behaviour. New York: Oxford University Press.

Moores, Shaun (1988) 'The Box on the Dresser: Memories of Early Radio and Everyday Life', Media, Culture and Society, Vol.10, No. 1: 23-40.

Morley, David (1980) The 'Nationwide' Audience. Structure and Decoding. London: British Film Institute.

Morley, David (1986) Family Television: Cultural Power and Domestic Leisure. London: Comedia.

Neale, Steve (1990) 'Questions of Genre', Screen, Vol. 31, No. 1: 45-66.

O’Donohoe, Stephanie (1997) 'Leaky Boundaries: Intertextuality and Young Adult Experiences of Advertising', in Nava, Mica; Andrew Blake; Iain MacRury \& Barry Richards (eds.) Buy this Book: Studies in Advertising and Consumption. London: Routledge.

Schutz, Alfred (1962) Collected Papers, Volume I: The Problem of Social Reality. The Hague: Martinus Nijhoff.

Schutz, Alfred \& Thomas Luckman (1973) The Structures of the Life-World. Evanston: Northwestern University Press.

Silverstone, Roger; Eric Hirsch \& David Morely (1992) 'Information and Communication Technologies and the Moral Economy of the Household', in Silverstone, Roger \& Hirsch, Eric (eds.) Consuming Technologies: Media and Information in Domestic Spaces. London: Routledge.

Thompson, John B (1995) The Media and Modernity: A Social Theory of The Media. Cambridge: Polity Press. Todorov, Tzvetan (1978/1990) Genres in Discourse. New York: Cambridge University Press.

Williams, Raymond (1974) Television: Technology and Cultural Form. London: Fontana. 